\title{
TEMPOROMANDIBULAR JOINT ANKYLOSIS - 'KNOWING WHEN NOT TO OPERATE': CASE REPORT AND QUALITATIVE SYSTEMATIC REVIEW OF LITERATURE
}

\author{
Kavish Kapoor ${ }^{1}$, Arunkumar Shadamarshan ${ }^{2}$, Rohit Sharma $^{3}$, and Nitesh Agrawal $^{1}$ \\ ${ }^{1}$ Military Hospital Jalandhar Cantt \\ ${ }^{2}$ Wangchuck Lo Dzong Military Hospital \\ ${ }^{3}$ Command Military Dental Centre (Western Command)
}

January 27, 2022

\begin{abstract}
Temporomandibular Joint Ankylosis(TMJA) may manifest in patients with several predisposing systemic conditions. A case of extraarticular TMJA is presented in a patient diagnosed with Fibrodysplasia Ossificans Progressive(FOP) is presented. The features, diagnosis and management of TMJA superimposed on this condition is presented through a qualitative systematic review of literature.
\end{abstract}

\section{Hosted file}

Manuscript.doc available at https://authorea.com/users/457472/articles/554245temporomandibular-joint-ankylosis-knowing-when-not-to-operate-case-report-andqualitative-systematic-review-of-literature 


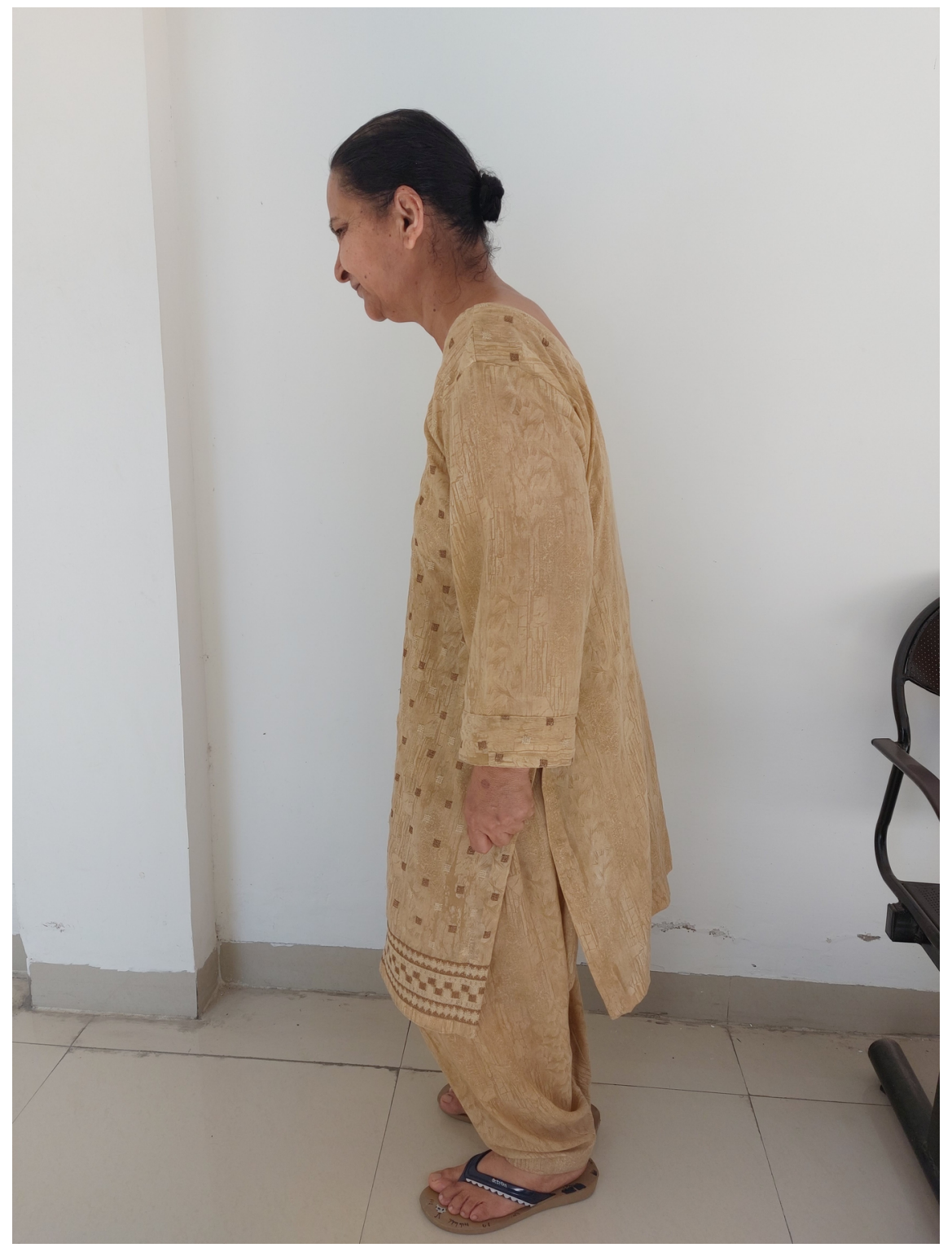




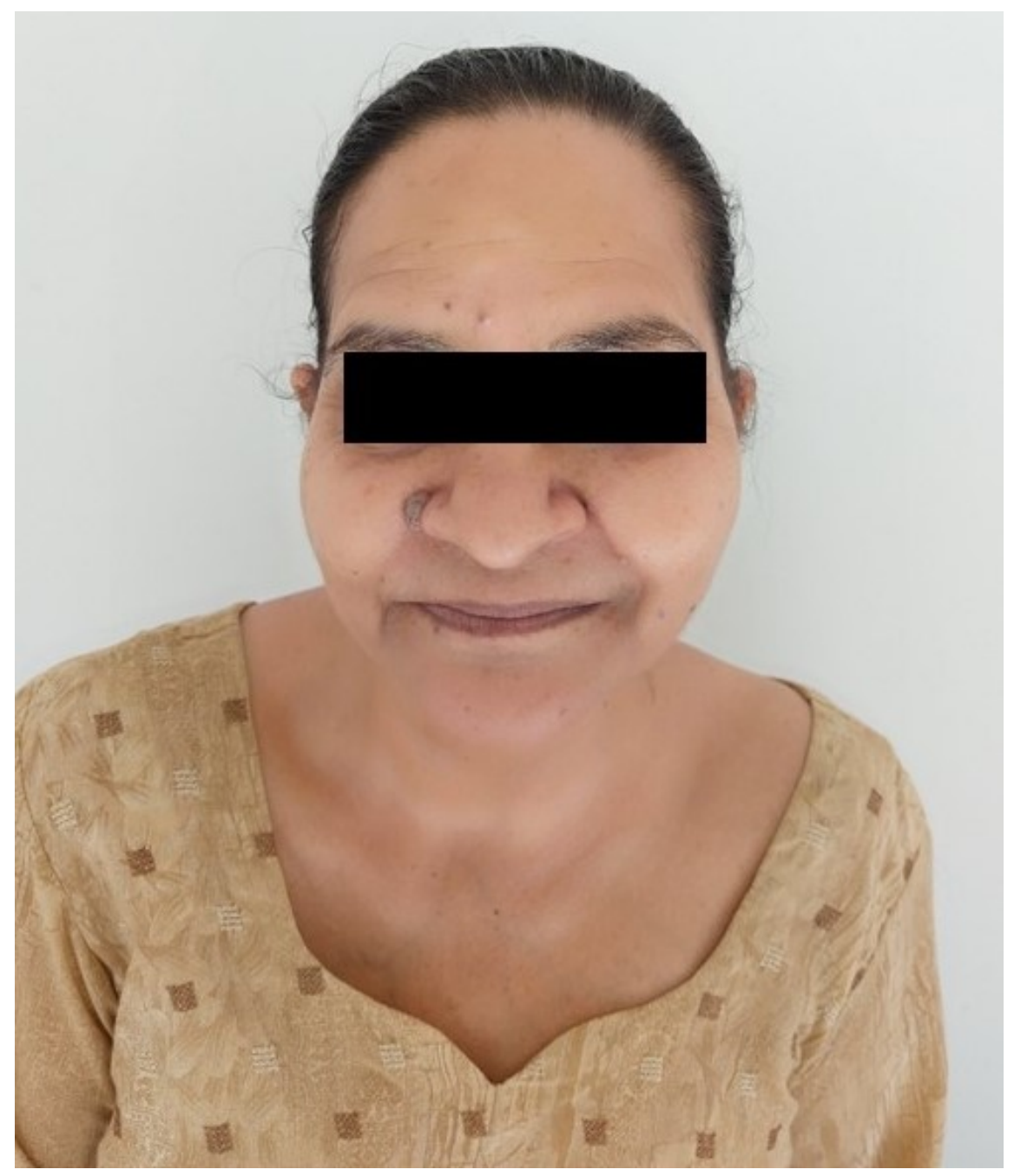




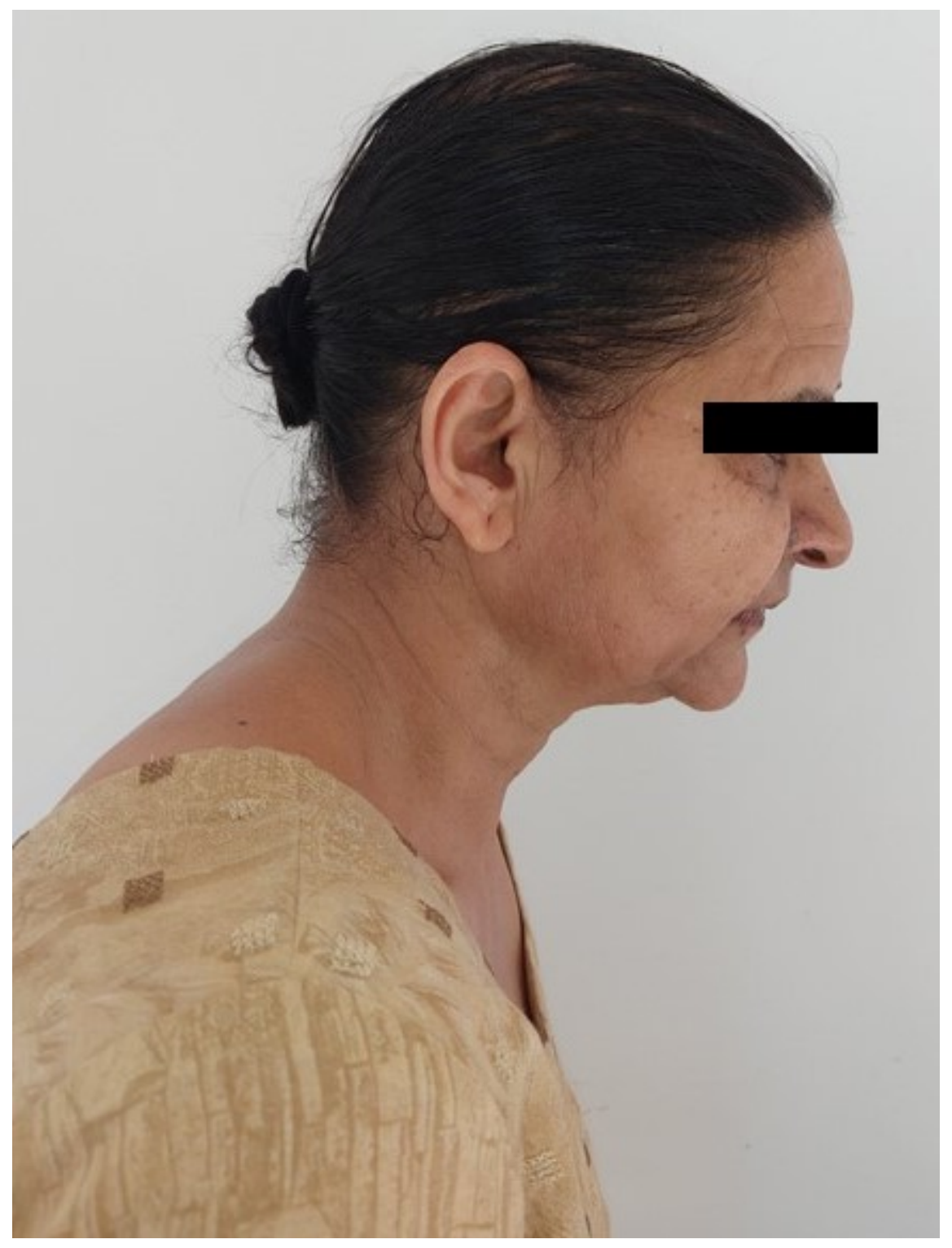




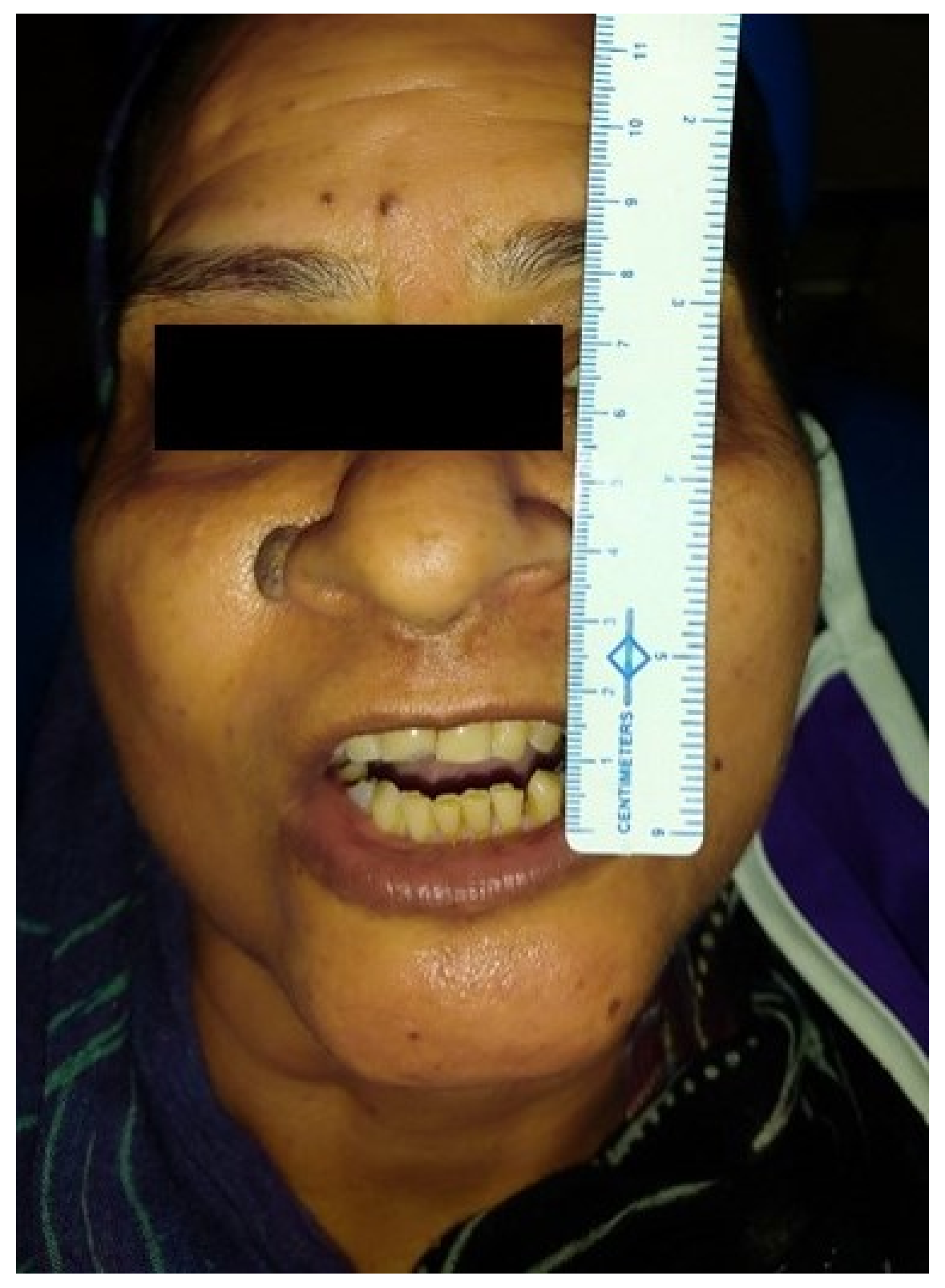




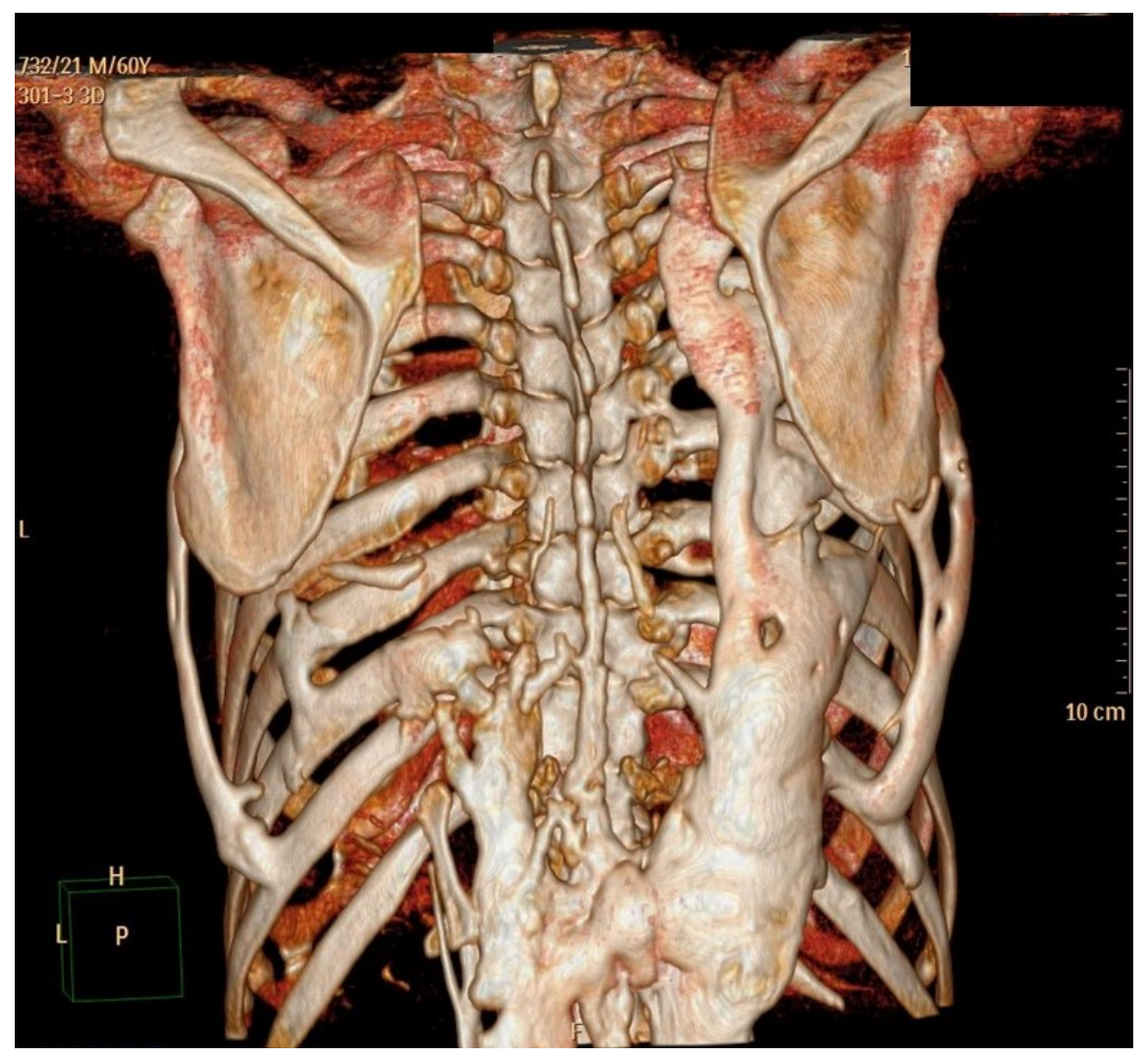




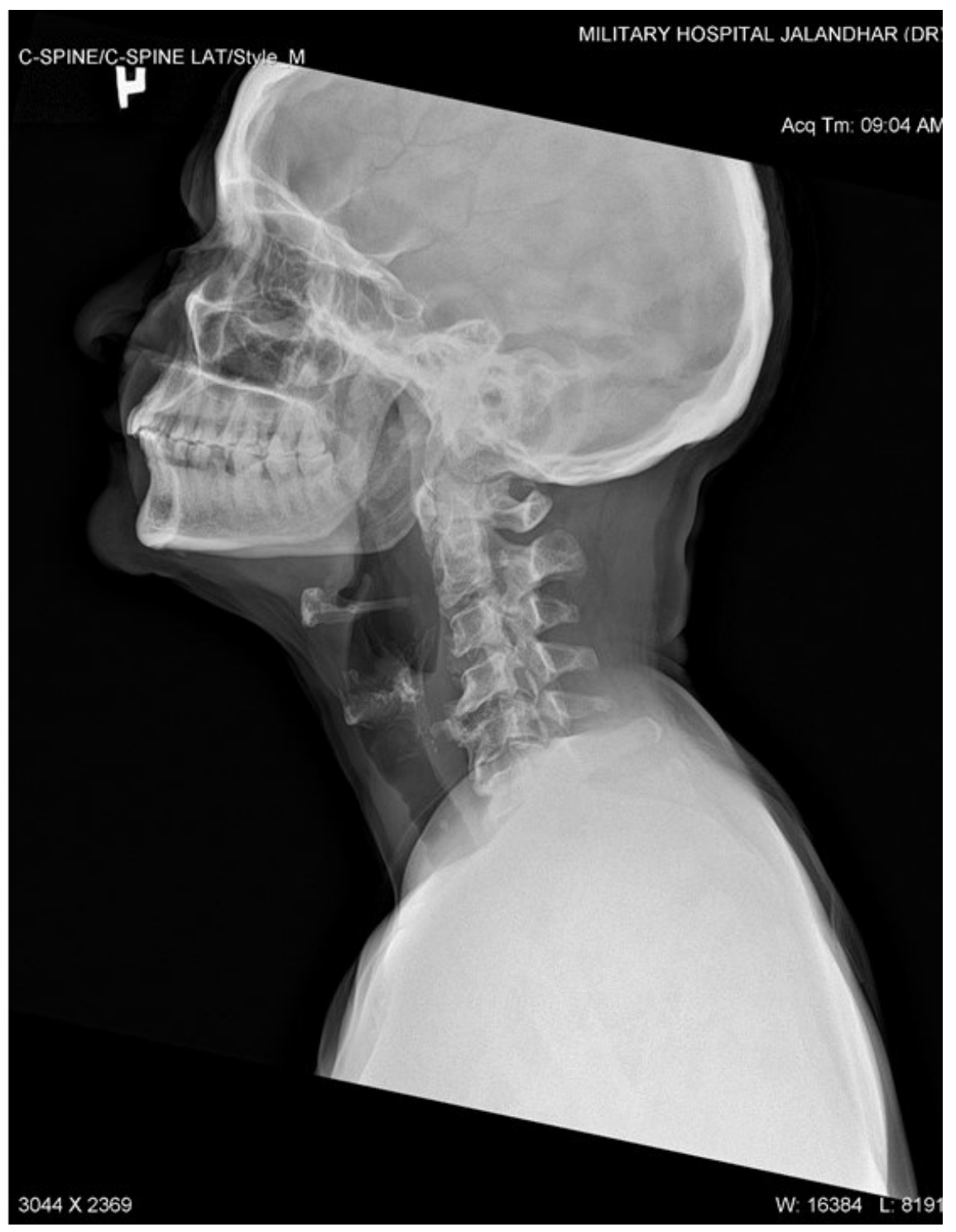



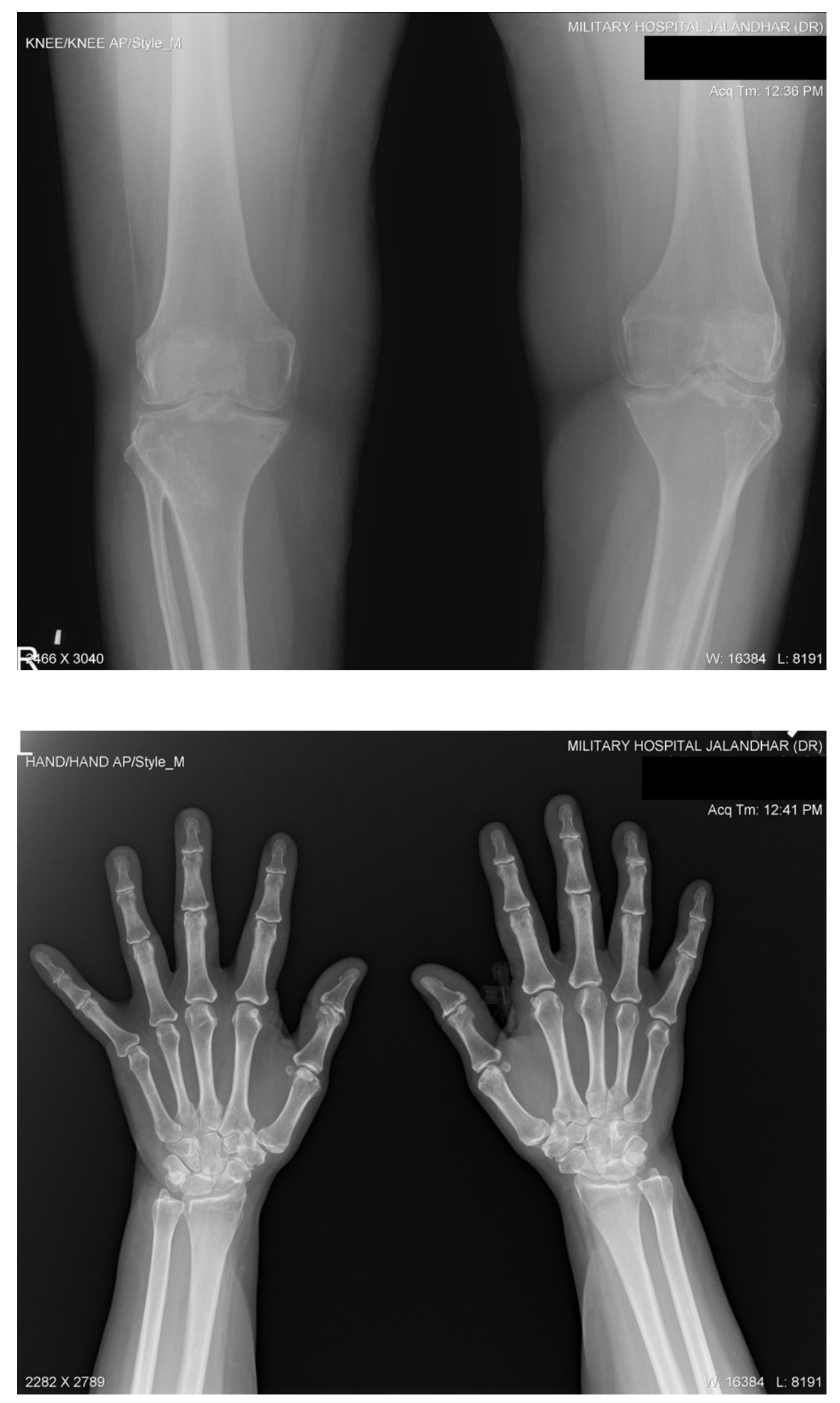

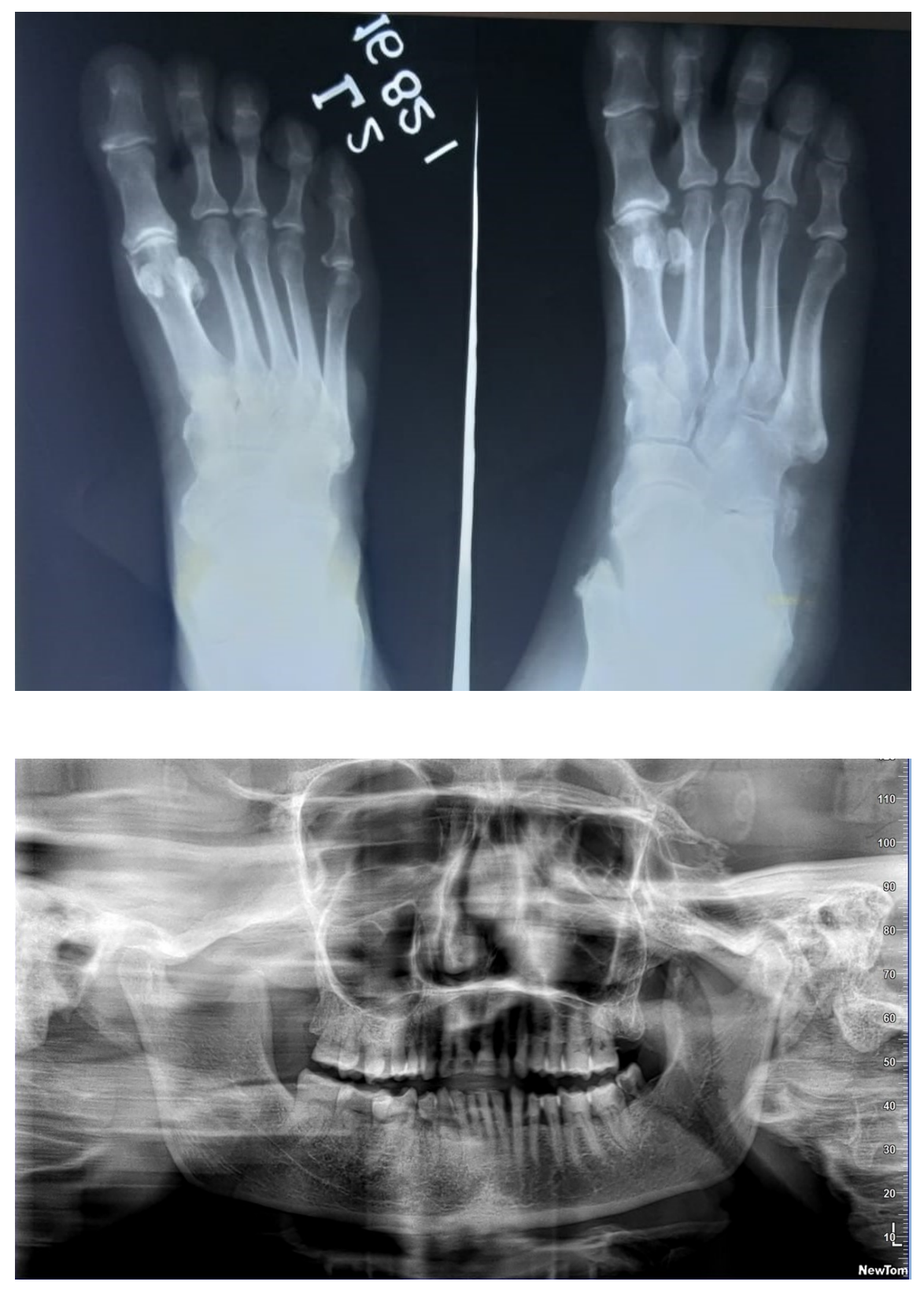

